\title{
Cloned Multipotential Precursors from the Mouse Cerebrum Require FGF-2, Whereas Glial Restricted Precursors Are Stimulated with Either FGF-2 or EGF
}

\author{
T. J. Kilpatrick a and P. F. Bartlett \\ The Walter and Eliza Hall Institute of Medical Research, Parkville 3050, Melbourne, Australia
}

Fibroblast growth factor-2 (FGF-2) and epidermal growth factor (EGF) have both been reported to stimulate precursors in the developing CNS. To clarify these effects, we used clonal analysis to determine the lineage potential of precursors stimulated with each factor, at two stages of development. It was found that in cells isolated from the cerebrum of embryonic day 17 (E17) mice, FGF-2 stimulated both a multipotential precursor, which gave rise to neurons and astrocytes, and a committed glial precursor. In contrast, EGF only stimulated the glial restricted precursor. Thus, it appears that the multipotential cell, previously identified to be present at $E 10$, remains selectively responsive to FGF-2, and that the EGF responsiveness observed at E17 reflects the presence of a new restricted class of precursors, rather than a switch in factor specificity of the multipotential cell.

[Key words: multipotential precursors, neuronal differentiation, glia, fibroblast growth factor, epidermal growth factor, clonal analysis]

Recent experiments have shown that multipotential precursor cells exist within the neuroepithelial cell population at the earliest phase of CNS development (Kilpatrick and Bartlett, 1993). However, the lineage potential of precursor cells identified later in ontogeny remains controversial. Clonal analysis performed on septal cells isolated from embryonic day 13.5-14.5 (E13.5-14.5) rats suggests that some of these cells also have multipotential capacity (Temple, 1989). On the other hand, analysis of cell lineage by retroviral markers (Sanes et al., 1986; Price et al., 1987), has shown only a small percentage of clones contain both neurons and astrocytes (Walsh and Cepko, 1992); the vast majority of clones consisted of cells committed to a single lineage (Luskin et al., 1988; Price and Thurlow, 1988; Grove et al., 1993; Luskin et al., 1993), suggesting that the majority of neurons and astrocytes arise in vivo from separate precursor cells.

Although neurogenesis is completed in the mammalian cerebrum by late embryogenesis, recent reports have suggested that neuronal precursor cells may not only exist throughout ontogeny

\footnotetext{
Received Feb. 7, 1994; revised Nov. 10, 1994; accepted Dec. 2, 1994.

This work was supported by the National Health and Medical Research Council of Australia. We also gratefully acknowledge the technical assistance of Ms. V. Likiardopoulos.

Correspondence should be addressed to Dr. Perry F. Bartlett, The Walter and Eliza Hall Institute of Medical Research, Grattan Street, Parkville 3050, Melbourne, Australia.

"Present address: The Salk Institute for Biological Sciences, 10010 North Torrey Pines Road, La Jolla, CA 92037

Copyright (C) 1995 Society for Neuroscience $0270-6474 / 95 / 153653-09 \$ 05.00 / 0$
}

but that they persist in the adult (Reynolds and Weiss, 1992; Richards et al., 1992; Lois and Alvarez-Buylla, 1993). In two of these studies, either exogenous fibroblast growth factor-2 (FGF-2) (Richards et al., 1992) or epidermal growth factor (EGF) (Rcynolds and Wciss, 1992) was required to stimulatc the proliferation of the neuronal precursors in vitro. The epigenetic conditions which stimulate the in vitro development of murine E10 neuroepithelial cells have already been investigated (Murphy et al., 1990; Drago et al., 1991a; Kilpatrick and Bartlett, 1993; Nurcombe et al., 1993). In particular, FGF-2, has been found to stimulate the proliferation of these cells (Kilpatrick and Bartlett, 1993), soluble growth factors produced by the immortalized astrocytic precursor cell line Ast-1 induce their neuronal differentiation and high cell density promotes astrocytic differentiation (Kilpatrick et al., 1993). In these reports, EGF failed to exert an effect. However, EGF has been shown by other groups to provide a mitogenic stimulus for E17 rat retinal neuroepithelial cells (Anchan et al., 1991) and E14 mouse striatal precursors (Reynolds et al., 1992). A recent report (Lillien and Cepko, 1992) suggests that these findings could be explained by differences in the responsiveness of precursor cells at different developmental stages. However, other reports suggest that there may be separate precursor populations which respond to specific, and possibly different, growth conditions (Reynolds and Weiss, 1992; Richards et al., 1992).

To determine the proliferative capacity, lineage potential and growth factor responsiveness of CNS precursors isolated at different developmental stages, we have studied the effects of FGF-2 and EGF upon E10 and E17 precursors. At high cell density, E10 precursor cells proliferated in response to FGF-2 but not EGF; whereas E17 precursors proliferated in response to either FGF-2 or EGF. Clonal analysis of the E17 precursors revealed two precursor populations: first, multipotential precursors which could only be stimulated by FGF- 2 and second, precursors restricted to the glial lineage, which responded to both FGF-2 and EGF.

\section{Materials and Methods}

Isolation of EIO neuroepithelial and E17 cerebral cells. Neural cells were isolated from the telencephalon and mesencephalon of E10 mice and from the cerebrum of E17 mice, using methods previously described for the isolation of E10 ncurocpithelial cells (Drago et al., 1991b). In the case of the E17 dissection, specific care was taken to remove the olfactory bulbs, the striatum and the developing hippocampus, prior to the initial trypsinization step. An average of $5 \times 10^{4}$ cells were obtained from the cerebral hemispheres of each E17 mouse.

Culture of EIO and E17 cells at high cell density. Tritiated-thymidine ( ${ }^{3} \mathrm{H}$-thymidine) incorporation assays were performed using high density cultures grown in wells in HL-A plates (Lux, USA). Fibroblast growth 
factor-2 (Boehringer Mannheim, Germany) and EGF (human recombinant, a gift of Dr. B. Whitehead, Ludwig Institute, Melbourne) were added in serial dilution to wells in the plates, in the presence of Monomed medium (CSL, Aust.) and 10\% fetal bovine serum (FBS). Monomed medium consists of a 1:1 mix of RPMI medium and Dulbecco's modified Eagle's medium (4.5 gm/liter glucose), HEPES buffered essential medium (10 mM), and $0.8 \mathrm{gm} /$ liter sodium bicarbonate. The basal medium is supplemented by the addition of insulin, transferrin, sodium selenite, 2-mercaptoethanol, 2-aminoethanol, sodium pyruvate, glutamine, and bovine serum albumin-oleic acid complex. Embryonic day 10 and E17 neural cells were then added at a concentration of $5 \times$ $10^{3}$ cells per well, giving a final volume of $10 \mu \mathrm{l}$ per well. After a $3 \mathrm{~d}$ culture period, ${ }^{3} \mathrm{H}$-thymidine (final concentration, $0.025 \mu \mathrm{Ci} / \mathrm{ml}$ ) was added to each well in a volume of $5 \mu \mathrm{l}$ and the cells were cultured for a further $24 \mathrm{hr}$. The cells were then lysed by the addition of $2 \mu \mathrm{l}$ of 10 $M$ ammonium hydroxide and the contents of the wells were absorbed onto nitrocellulose disks, using a Titertek harvester (Flow, Finland). The wells were then washed three times with $0.1 \mathrm{mg} / \mathrm{ml}$ of denatured salmon sperm DNA (Boehringer Mannheim, Germany) and the nitrocellulose disks were washed three times with water and subsequently with methanol. The disks were dried, scintillation fluid (Canberra Packard, Aust.) was added, and the incorporated radioactivity from each immersed disk was counted, using a 2000 TRI-CARB, liquid scintillation analyzer.

Embryonic day 17 cultures ( $5 \times 10^{3}$ cells per well in HL-A plates), stimulated with EGF $(100 \mathrm{ng} / \mathrm{ml})$ in the presence of Monomed and $10 \%$ FBS, were also treated with $25 \mu \mathrm{M}$ inositol hexakisphosphate (Sigma, St. Louis). These cultures were assessed after $3 \mathrm{~d}$ in vitro for the generation of neurons, using morphological and immunohistochemical criteria (see below)

Culture and cloning of $E 17$ cerebral cells. Dissociated cells obtained from the above dissections were plated at a density of $5 \times 10^{5}$ cells/ wcll in 24 well plates (Linbro, Scotland) in Monomed containing $10 \%$ FBS, with either $20 \mathrm{ng} / \mathrm{ml} \mathrm{FGF-2} \mathrm{and} 8 \mu \mathrm{g} / \mathrm{ml}(1.1 \mathrm{U} / \mathrm{ml})$ heparin or $20 \mathrm{ng} / \mathrm{ml}$ EGF. The cells were incubated for $24 \mathrm{hr}$, washed in mouse tonicity phosphate-buffered saline (MTPBS), and incubated in $0.025 \%$ (w/v) trypsin (Boehringer Mannheim, Germany) for $5 \mathrm{~min}$, to dissociate the cells. The reaction was stopped by the addition of FBS and the cells were washed and resuspended in either Monomed with 10\% FBS, 20 $\mathrm{ng} / \mathrm{ml} \mathrm{FGF-2} \mathrm{and} 8 \mu \mathrm{g} / \mathrm{ml}$ heparin, Monomed with $10 \%$ FBS and 20 $\mathrm{ng} / \mathrm{ml}$ EGF or Monomed with $10 \%$ FBS, $20 \mathrm{ng} / \mathrm{ml}$ FGF-2, $8 \mu \mathrm{g} / \mathrm{ml}$ heparin, and $20 \mathrm{ng} / \mathrm{ml} \mathrm{EGF}$.

To clone these precultured cells, a single cell suspension was prepared by gently pipetting the solution and passaging it sequentially through $18,20,22$, and 24 gauge needles. The cells were plated by limiting dilution, at an average of 1 cell/well in $10 \mu \mathrm{l}$ in 60 well HL-A plates (Lux, USA). The cells were allowed to settle and the plates were then screened by phase microscopy for wells with a single cell. The location of the cell within each well was recorded, and it was verified that the clones proliferated in the same geographical region as this annotated position, to provide further evidence that they were generated from the identified cell. The cultures were refed with the culture medium every $3-4 \mathrm{~d}$, and the resultant proliferating clones (containing $>4$ cells) were assessed $10-14 \mathrm{~d}$ after plating.

A subpopulation of the clones grown in EGF, had their media removed after $7 \mathrm{~d}$ in vitro. These clones were then washed once in MTPBS, prior to the application of Monomed with $10 \%$ FBS, $20 \mathrm{ng} /$ $\mathrm{ml} \mathrm{FGF-2,} \mathrm{and} 8 \mu \mathrm{g} / \mathrm{ml}$ heparin. The phenotype of these clones was assessed $7 \mathrm{~d}$ after the medium was changed.

In a separate set of experiments, the dissociated cells were first plated at a cell density of $5 \times 10^{5}$ cells per well in 24 well plates in serumfree Monomed, in the presence of either FGF-2 $(20 \mathrm{ng} / \mathrm{ml})$ and heparin $(8 \mu \mathrm{g} / \mathrm{ml})$ or EGF $(20 \mathrm{ng} / \mathrm{ml})$. The cells were incubated for $24 \mathrm{hr}$, washed in MTPBS, and then dissociated in $0.025 \%(\mathrm{w} / \mathrm{v})$ trypsin. The reaction was stopped by the addition of FBS, the cells were washed in Monomed and then resuspended under the same culture conditions as those used for the initial bulk culture. The cells were then cloned, as detailed above, and refed every 3-4 d.

Subcloning was performed by washing the clones with MTPBS, trypsinization $(0.025 \%, \mathrm{w} / \mathrm{v})$, and resuspending the cells in the culture medium prior to replating. Cells were resuspended in either Monomed with $20 \mathrm{ng} / \mathrm{ml}$ FGF-2 and heparin $(8 \mu \mathrm{g} / \mathrm{ml})$, Monomed with $10 \%$ FBS, 20 $\mathrm{ng} / \mathrm{ml} \mathrm{FGF-2}$ and heparin, Monomed with $20 \mathrm{ng} / \mathrm{ml}$ of EGF or Monomed with $10 \% \mathrm{FBS}$ and $20 \mathrm{ng} / \mathrm{ml}$ of EGF. The cells were then replated into wells in HL-A plates and their subsequent development was assessed by phase microscopy and by immunohistochemistry.
Culture of clones with conditioned medium from an astrocytic precursor cell line. Conditioned medium from, Ast-1, an N-myc immortalized astrocytic precursor cell line, was harvested by methods previously described (Kilpatrick et al., 1993). Epithelioid clones grown in vitro for $7 \mathrm{~d}$ had their culture medium removed, were washed once with MTPBS and were then cultured in the serum-free conditioned medium (diluted 1:2) derived from the Ast-1 cells. The cultures were refed with Ast- 1 conditioned medium daily, their morphology was reviewed by phase microscopy and their phenotype was assessed by immunohistochemistry $3 \mathrm{~d}$ after the initial addition of the conditioned medium.

Immunohistochemistry and counterstaining of clones. Cultures were assessed for the expression of neurofilament and microtubule-associated protein-2 (MAP-2), after methanol fixation, by using either polyclonal rabbit anti-150 kDa neurofilament antibodies (Chemicon, USA) or monoclonal anti-MAP-2 antibodies (Sigma) and a commercial immunoperoxidase-staining kit (Vectastain, USA). The wells were washed three times in MTPBS, $1 \%$ FBS, and preincubated for 30 min with normal goat serum, prior to further washing. The cells were then incubated with either anti-neurofilament antibodies (diluted 1:200) or antiMAP-2 antibodies (diluted 1:100) for $30 \mathrm{~min}$, washed three times, and incubated with biotinylated goat anti-rabbit antibody, diluted 1:200, for $45 \mathrm{~min}$. After further washing, the wells were incubated in avidinbiotin-peroxidase solution, diluted 1:50, in MTPBS. The wells were washed again, and then $0.1 \% 3,3^{\prime}$-diaminobenzidine tetrahydrochloride (Dakopatts, USA) and hydrogen peroxide $0.1 \%(\mathrm{w} / \mathrm{v})$ were added for $10 \mathrm{~min}$. The wells were finally washed three times in MTPBS and once with water and mounted in MTPBS/glycerol (1:9) with 2.6\% 1,4-diazobicyclo-(2,2,2)-octane (DABCO) (Merck, Aust) and assessed by bright-field microscopy.

To assess for the presence of glial fibrillary acidic protein (GFAP), the clones were first fixed in methanol at $-20^{\circ} \mathrm{C}$ for $30 \mathrm{~min}$ and washed three times in MTPBS, 1\% FBS. The cultures were then assessed by either immunoperoxidase or immunofluorescent staining. When the former technique was employed, the same procedure was used as for neurofilament staining (sec above), except that polyclonal rabbit anti-GFAP antibodies (Dakopatt, Denmark), diluted 1:50 in MTPBS, 1\% FBS were applied for $30 \mathrm{~min}$, instead of the anti-neurofilament antibodies. When irnmunofluorescent staining was performed, the primary antibody was added first for $30 \mathrm{~min}$. The cells were then washed three times, and incubated with a fluorescein-conjugated sheep anti-rabbit antibody (Silenus, Aust.) diluted 1:50 for $30 \mathrm{~min}$. The wells were rewashed three times in MTPBS, 1\% FBS and once in water and were then mounted in DABCO with glycerol and assessed by fluorescence microscopy, using epiillumination.

Control staining was also performed in all of these experiments, using diluted rabbit serum, instead of the primary antibody. Wells scored as negative had the same background staining as the negative controls.

To assess for the percentage of MAP-2 positive cells within cultures, counterstaining was performed, using hematoxylin. The wells were first washed with $\mathrm{H}_{2} \mathrm{O}$ and hematoxylin $(0.3 \%)$ was then added for 1 min. The wells were subsequently washed with $\mathrm{H}_{2} \mathrm{O}$ and then with Scott's tap water. After a further minute, aquamount (Gurr, England) was added and the cultures were coverslipped.

\section{Results}

The proliferative response of embryonic neural cells to epigenetic factors is dependent upon the developmental stage

It has been previously determined that E10 neuroepithelial precursor cells proliferate in response to FGF-2, both at high cell density (Murphy et al., 1990) and within clonal populations (Kilpatrick and Bartlett, 1993). However, EGF fails to induce the proliferation of neuroepithelial cells, as assessed by clonal analysis (Kilpatrick and Bartlctt, 1993). As other investigators have reported a stimulatory effect of EGF on neural precursors (Anchan et al., 1991; Reynolds and Weiss, 1992; Reynolds et al., 1992), we decided to test the relative stimulatory effects of FGF-2 and EGF upon E10 and E17 cerebral neural precursors, at high density $\left(5 \times 10^{3}\right.$ cells/well in HL-A plates $)$. The proliferation of the cells was assessed by quantitating ${ }^{3} \mathrm{H}$-thymidine incorporation over the final $24 \mathrm{hr}$ of a $4 \mathrm{~d}$ culture period. The results confirmed that E10 neuroepithelial cells, isolated from 
A
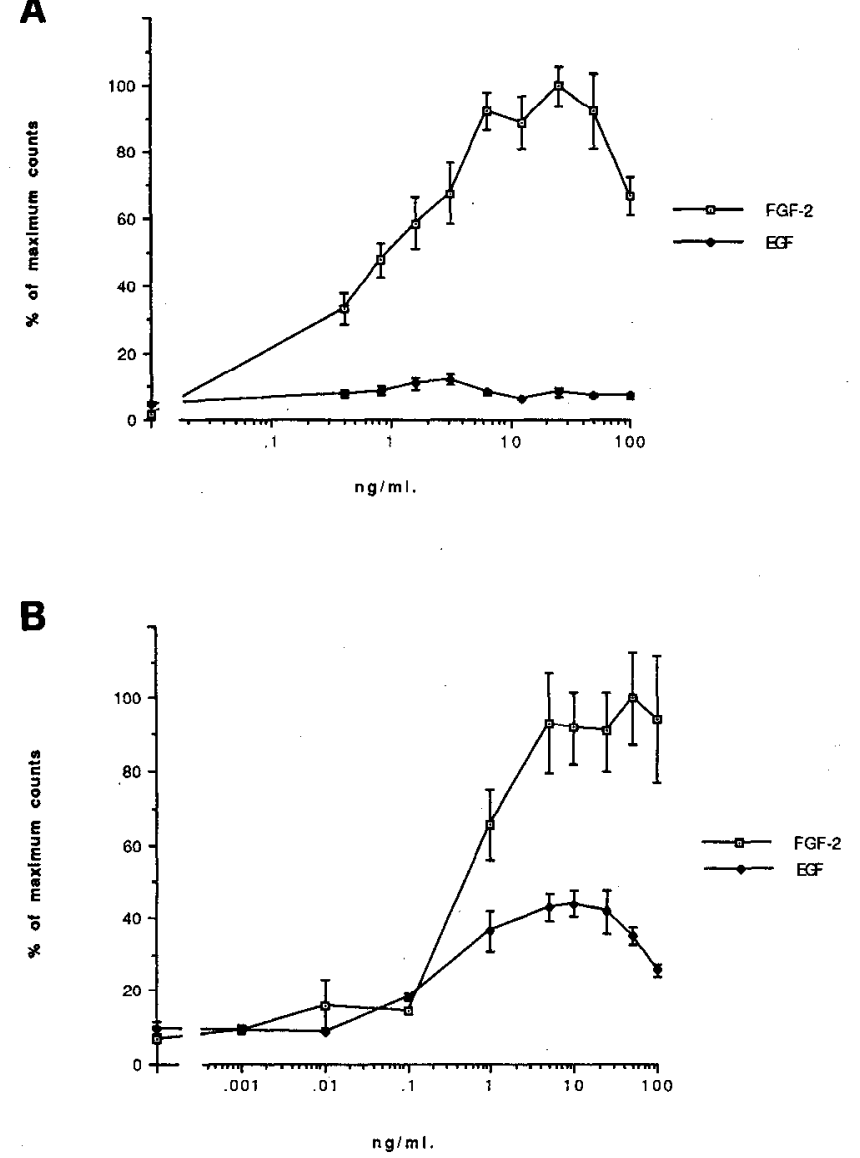

Figure 1. The effects of FGF-2 and EGF on the proliferation of E10 neuroepithelial cells $(A)$ and $\mathrm{E} 17$ cerebral cells $(B)$, as determined by tritiated-thymidine incorporation. For each concentration of the growth factor, the result represents the mean and the SEM from six replicate cultures. Shown are the results of one of two separate experiments which gave similar results. For the E10 experiment, baseline counts were $2.4 \times 10^{3} \mathrm{cpm}$ and maximal counts with FGF were $1.3 \times 10^{5}$ $\mathrm{cpm}$; there was no significant proliferative response to EGF. For the E17 experiment, baseline counts were $9.2 \times 10^{2} \mathrm{cpm}$, maximal counts in response to $\mathrm{FGF}$ were $1.3 \times 10^{4} \mathrm{cpm}$ and maximal counts in response to EGF were $6.1 \times 10^{3} \mathrm{cpm}$.

the telencephalon and mesencephalon, proliferated in response to FGF-2 in a dose-dependent fashion but failed to proliferate in response to EGF at concentrations ranging from $0.4-100 \mathrm{ng} /$ $\mathrm{ml}$ (Fig. 1A). However, E17 precursor cells proliferated in response to both EGF and FGF-2 in a dose-dependent fashion, although the maximal proliferative response with EGF was only $44 \%$ of that induced by FGF-2 (Fig. $1 B$ ). Both the FGF-2 and EGF treated E17 cultures contained large numbers of both neurofilament positive and GFAP positive cells (Fig. $2 A-D$ ). Closer examination revealed morphological differences between the FGF-2 and EGF cultures. With FGF-2, there was typically an extensive cellular substratum of GFAP positive cells upon which the neurofilament positive cells spread and the latter cells often exhibited thick, single, and poorly developed neurites (Fig. 2A). In the presence of EGF, the substratum was less uniform and, sometimes incomplete. In these regions, neurofilament positive cells, which characteristically possessed well-developed neurites throughout the culture, often formed discrete, "whorled" structures (Fig. 2C).
Clones of E17 neural cells were generated in response to either FGF-2 or EGF

Nlthough the above results indicated that both FGF-2 and EGF. could stimulate the proliferation of E17 cells, they did not clarify whether these factors acted directly upon precursor cells or indirectly, by upregulating the production of other trophic factors. To address this question, we undertook a clonal analysis. In a series of experiments using E17 neural cells, proliferating clonal populations were generated with either FGF-2 (330 clones from 12,798 plated cells) or EGF (101 clones from 5060 plated cells). This result was in marked contrast to clonal analysis of the E10 neuroepithelial population, which had demonstrated that these cells proliferated exclusively in response to FGF-2 (Kilpatrick and Bartlett, 1993). The cloning efficiencies varied between experiments; however, in those experiments in which FGF-2 and EGF were directly compared, the cloning efficiency was $4.9 \%$ with FGF-2 (109 clones from 2238 plated cells) and $2.0 \%$ with EGF (40 clones from 2040 plated cells). It was also found that the addition of FBS was required to generate proliferating clones with either FGF-2 or EGF; none were generated in the absence of FBS.

\section{Neural phenotype of E17 clones generated with FGF-2 or EGF}

The majority of clones generated with FGF-2 (88.7\%) and all the clones generated with EGF, consisted of flat, epithelioid cells which grew as either subconfluent or confluent monolayers at the base of the tissue culture wells, and which contained between 4 and more than a thousand cells. The phenotype of the cells within these clones was further determined by immunostaining for the expression of ncurofilament and GFAP. None of these clones contained neurofilament positive cells. However, whether generated with either FGF-2 or EGF, a large percentage of these clones, $71 \%$ (144 of 202) with FGF-2 and $80 \%$ (16 of 20) with EGF, contained GFAP positive cells, as shown in the photomicrographs of representative clones, in Figure $3, A$ and $B$. In these two clones, $100 \%$ of the cells stained positively for GFAP. They are representative of the epithelioid clones which contained GFAP positive cells; in all such clones, the vast majority of cells stained positively for GFAP, although quantitation was often difficult, due to a propensity for cells to heap up in multiple layers at the edges of the tissue culture wells. These clones differed from epithelioid clones previously derived from E10 neuroepithelial cells in two ways: first, although $65 \%$ of the E10 clones contained some GFAP positive astrocytes, they comprised, on average, only $14 \%$ of the cells in each clone; and second, and most importantly, $24 \%$ of the E10 clones contained some neurofilament positive neurons (Kilpatrick and Bartlett, 1993).

A second clonal phenotype was also observed with E17 cells, but this subtype was only generated in the presence of FGF-2, and represented $11.3 \%$ (29 of 287) of the FGF-2 treated clones. These clones often contained tightly packed clusters of cells which formed spheroids (Fig. $4 A$ ). Within a week of plating, the spheroids flattened (Fig. 4B) and subsequently displayed considerable proliferative potential, with individual wells containing up to 4000 cells. Once flattened, these clones contained two discrete types of cells: flat, epithelioid cells and elongated cells, some of which resembled differentiated neurons. To further assess the phenotype of the cells within these clones, they were analyzed for the expression of either neurofilament or MAP-2. Neurofilament and MAP-2 positive cells were identified, with 

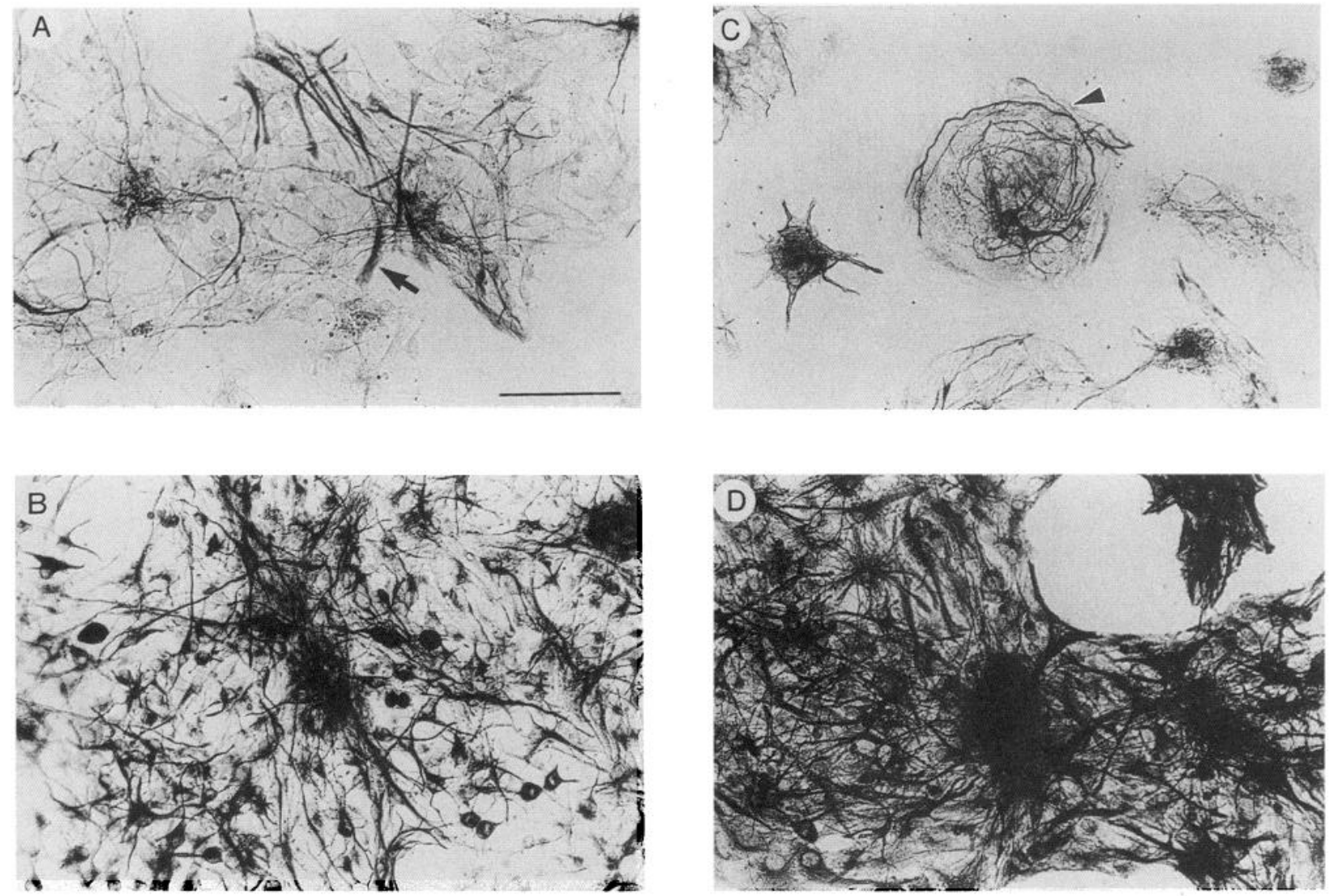

Figure 2. Photomicrographs of E17 cerebral cells cultured at $5 \times 10^{3}$ cells per well with either FGF-2 $(A, B)$ or EGF $(C, D)$ and stained by immunoperoxidase for the expression of either the neurofilament $(A, C)$ or GFAP $(B, D)$ antigens. Both factors promoted the appearance of many neurofilament and GFAP positive cells. In the presence of FGF-2, the neurofilament positive cells included cells with well developed neurites and cells with single, thick processes (arrow), whereas, in the presence of EGF, the neurofilament positive cells possessed well developed neurites and formed discrete, "whorled" structures, especially in regions where the cellular substratum was incomplete $($ arrowhead $)(C)$. Scale bar, $100 \mu m$.

both flat and elongated cells staining positively (Fig. 4C,D). On average, $95 \%(n=6)$ of the cells within individual clones expressed MAP-2.

These results indicated that a precursor cell capable of generating neurons had been isolated from the E17 cerebrum and that this cell proliferated in response to FGF-2 but not to EGF. However, it remained to be determined if this precursor either exhibited a multipotential differentiation capacity or if it was restricted to the neuronal lineage. To investigate this, a subset of the clones identified to contain neurofilament positive cells, by immunoperoxidase (Fig. $5 A$ ), was assessed by immunofluorescence for the expression of GFAP and 14 of the 15 analyzed clones contained GFAP positive astrocytes (Fig. 5B). This observation confirmed that a precursor cell, capable of generating both neurons and astrocytes, had been identified.

\section{Recloning capacity of E17 precursors}

Previous work with E10 multipotential proliferative clones had revealed that $>50 \%$ of the progeny of these cells gave rise to proliferating subclones, indicating that each clone contained a large percentage of precursor cells. However, when the FGF-2 stimulated E17 clones containing both neurons and glia were dissociated and replated with FGF-2, a mean of only $1.7 \%$ of the cells (range $0-2.7 \%$, from three independent experiments, with 600 cells assessed per experiment) gave rise to proliferating clones. This is not unexpected, given the large percentage of differentiated cells, neurons, and glia, in each clone.
The replating of cells from E17 epithelioid clones, which had been shown to be restricted to cells of the glial lineage, also showed a low rate of recloning (mean $2.2 \%$, range $0.7-4 \%$, from three independent experiments, with 600 cells assessed per experiment), regardless of whether the cells were replated in the presence of either FGF-2 or EGF. Again this was not unexpected, given the high frequency of GFAP positive cells in individual clones. Indeed, the large number of single GFAP positive cells in the wells suggests that, in isolation, these cells are incapable of proliferation with either FGF-2 or EGF.

\section{EGF stimulates precursors that are restricted to the glial lineage}

We further investigated the lineage potential of the clones generated in the presence of EGF and the epithelioid clones generated in FGF-2, to assess if neurons could be induced by altering the culture conditions. As we had previously shown that E10 epithelioid clones, which did not contain morphologically identifiable neurons, could be converted into clones with large numbers of neurofilament positive neurons by incubating them with medium conditioned by the cell line, Ast-1, (Kilpatrick and Bartlett, 1993; Kilpatrick et al., 1993), Ast-1 conditioned medium was added to 30 of the epithelioid, E17 clones. None of the E17 clones changed morphology or expressed neurofilament reactivity. This issue was further investigated by adding FGF-2 to EGFstimulated clones after they had been grown for $7 \mathrm{~d}$ in vitro ( $n$ $=56$ ). We again failed to detect the reemergence of a multi- 

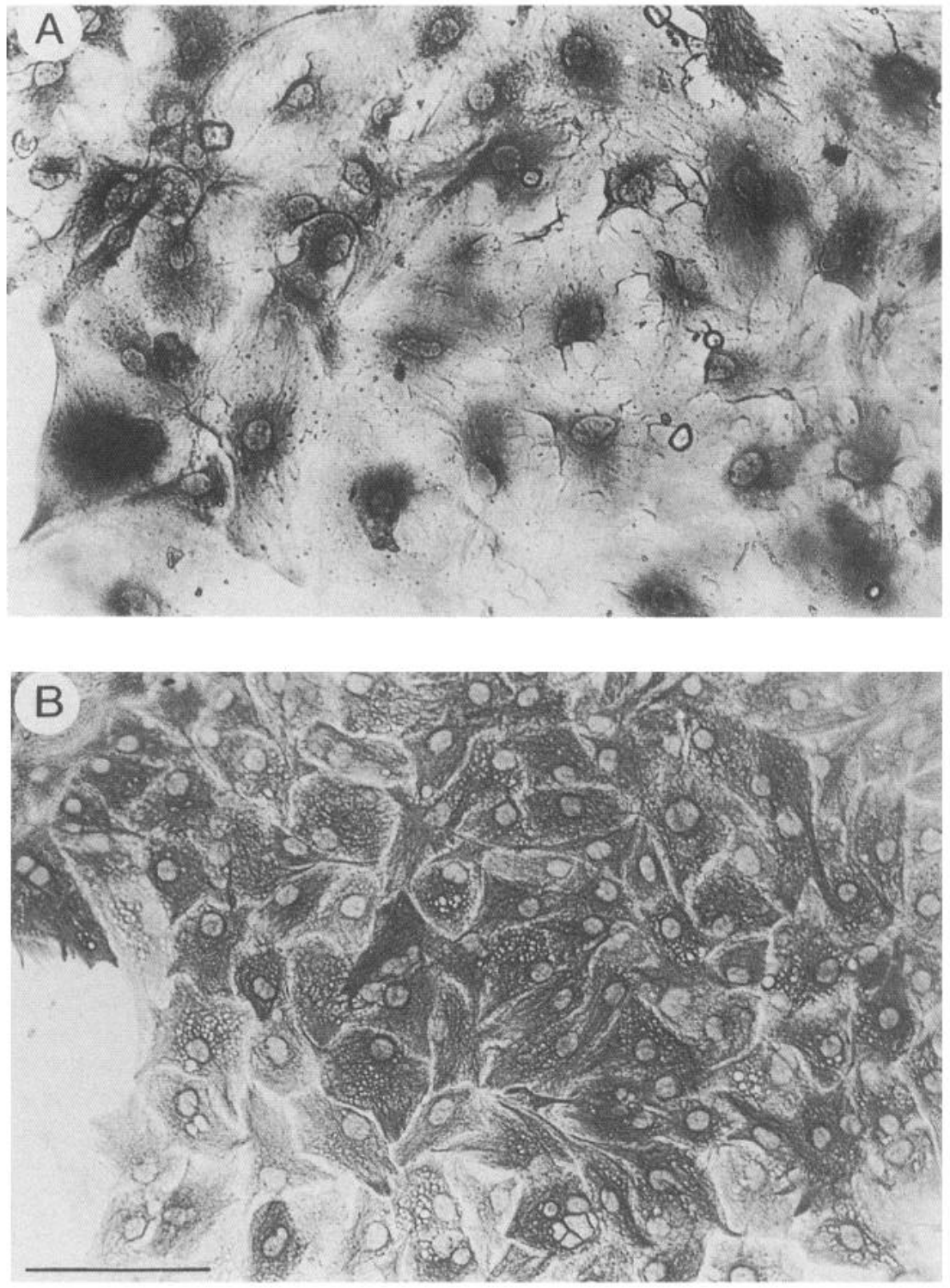

Figure 3. Photomicrographs of two clones generated from E17 cerebral cells in the presence of either FGF-2 $(A)$ or EGF $(B)$. Immunoperoxidase staining for the expression of GFAP, revealed that these particular clones consisted of mainly astrocytes which tended to be more vacuolated when grown in the presence of EGF $(B)$. Scale bar, $100 \mu \mathrm{m}$. potential phenotype, as assessed by the absence of either neurofilament or MAP-2 positive progeny (i.e., cells committed to the neuronal lineage) within any of these clones.

It remained formally possible that multipotential precursors were being restricted to the astrocytic lineage by EGF. To investigate this, we plated the E17 cells in both FGF-2 and EGF, simultaneously. The mixture of phenotypes generated under these conditions was similar to that generated in the presence of FGF-2, alone: 77 epithelioid clones and 9 clones containing cells committed to the neuronal lineage. These data indicate that the effect of EGF is not predominant and suggest that EGF does not act to restrict the fate of multipotential precursors to the glial lineage. It is thus probable that the epithelioid clones were derived from E17 precursors that did not have the capacity to generate neurons and that they represented a population of glial restricted progenitors.

These data also raised the possibility that the generation of neurons in high density cultures of E17 cells stimulated with EGF, could be secondary to the production of endogenous factors, possibly FGF. We explored this issue further by incubating E17 neural cells at high density $\left(5 \times 10^{3}\right.$ cells/well in HL-A plates) with EGF, either with or without inositol hexakisphosphate $\left(\mathrm{InsP}_{6}\right)$, which has previously been reported to block the binding of FGF-2 to its extracellular receptors (Sherman et al., 1993). The addition of Ins $_{6}$ not only decreased overall cellular proliferation (Bartlett, unpublished observations) but, most importantly, it also resulted in a significant reduction in the percentage of morphological neurons (cells with neurites, confirmed by neurofilament staining) generated within the EGF-stimulated cultures $\left(7.6 \% \pm 8.2 \%\right.$ of total cells with $\mathrm{InsP}_{6}$ and $67.3 \% \pm$ $15.4 \%$ of total cells without InsP $_{6}$; mean \pm SEM, with 500 cells counted in each condition in three independent experiments).

\section{Discussion}

These experiments demonstrate that multipotential precursor cells persist within the mammalian cerebrum at the time of completion of cortical neurogenesis (E17 in the mouse; Angevine and Sidman, 1961) and that these precursors, like those identified at E10 (Kilpatrick and Bartlett, 1993), proliferate in response to FGF-2, in conjunction with serum-associated factors. This finding, along with the recent demonstration of the presence of precursors within the adult brain, capable of generating neu- 

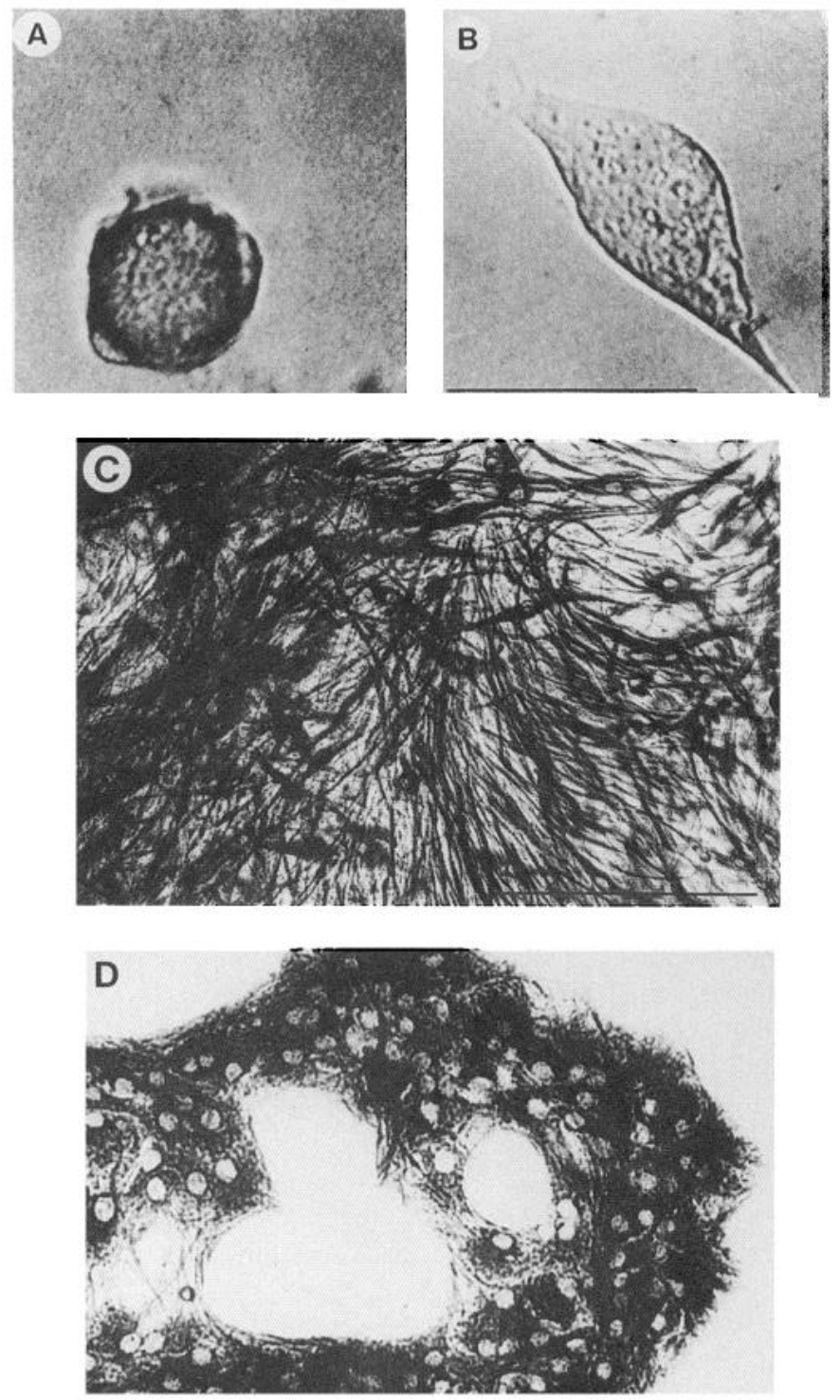

Figure 4. Photomicrographs of FGF-2 treated clones derived from E17 neural cells that grew initially as spheroids $(A)$ but subsequently flattened, and spread on the substratum $(B)$. After further growth, immunoperoxidase staining, for the expression of either neurofilament or MAP-2 antigens was performed and revealed the presence of large numbers of neurofilament and MAP-2 positive cells, as shown in $C$ and $D$, respectively. Scale bar, $100 \mu \mathrm{m}$.

rons and glia (Reynolds and Weiss 1992, Richards et al., 1992), suggests that a population of multipotential precursor cells probably exists in the mammalian brain throughout life. In the postneurogenic animal, it has been suggested (Morshead and van der Kooy, 1992), and recently demonstrated (Lois and AlvarezBuylla, 1993), that such multipotential precursors may be located predominantly in the subventricular zone, especially in the region surrounding the lateral ventricles.

Clonal analysis has shown that the relative proportion of multipotential precursors amongst FGF-2-responsive, E17 cells $(11.3 \%)$, is similar to that previously observed in the E10 neuroepithelium (12\%; Kilpatrick and Bartlett, 1993). The cloning efficiency was also surprisingly high at E17, especially given that the percentage of postmitotic cells in the developing cerebrum of the rat increases from around $15 \%$ at E11 to $75 \%$ by
E17 (Maric et al., 1992). It is tempting to speculate that the similar cloning efficiencies at E10 and E17 (3.8\% and 4.9\%, respectively), could indicate the absolute number of multipotential precursors at E17 is at least as great as the number present at E10. Many of the E10 clones, however, were composed entirely of undifferentiated cells and thus, the phenotypic potential of the parent cell, which generated these clones, is not defined. Nevertheless, even if we assume that all the epithelioid clones at E10 (Type B clones, Kilpatrick and Bartlett, 1993) are multipotential, the estimated number of multipotential cells contained in the E17 cerebrum would exceed that in the E10 telencephalon and mesencephalon $\left(1.7 \times 10^{5}\right.$ cells compared with $0.59 \times 10^{5}$ cells); however, to rigorously explore this issue, relative cloning efficiencies at E10 and E17 would need to be directly compared.

Although there is no doubt that multipotential cells exist in the brains of both E10 and E17 mice, the properties of these precursors at the different ages do have intrinsic differences. For example, results from recloning experiments suggest that the progeny of E17 precursors have a vastly decreased ability to proliferate in comparison to the progeny of E10 precursors; this suggests first that, at least in vitro, E10 precursors can give rise to a large number of like cells, whereas E17 precursors may have limited self-renewal capacity and second, that the progeny of E17 precursors are more likely to be further down the differentiation pathway. The ability of E17 precursors to spontaneously give rise to large numbers of neurofilament positive cells in the presence of FGF-2, whereas progeny of E10 clones only exhibited significant neuronal differentiation in response to a second stimulus, provided by conditioned medium from the Ast-1 cell line (Kilpatrick and Bartlett, 1993), supports the second contention. An alternative explanation to the age-dependent variability in differentiative and proliferative potential of precursor progeny could be the differences in the maturity of the glial progenitors contained within the E10 and E17 clones. This would imply that astrocytes within the E17 clonal populations have a greater capacity to produce factors akin to those present in Ast-1 generated conditioned medium (Kilpatrick et al., 1993). It should be noted, however, that the neurofilament and MAP-2 positive cells generated with FGF-2 in both our E17 clonal (Fig. $5 A$ ) and high density cultures (Fig. 2A) sometimes exhibited only rudimentary neuritic outgrowth. In contrast, neurons in EGF treated high density cultures had well developed neurites, although differences in the neuronal morphologies within the FGF-2 and EGF cultures could have as much reflected differences in the cellular substrates within the two cultures, as direct effects of the growth factors upon the neuronal cells. Nevertheless, it has been previously reported (Mehler et al., 1993), that there is a hierarchy of growth factors involved in the regulation of neuronal differentiation and that FGF although necessary, is not, by itself, sufficient to complete neuronal differentiation, as assessed by morphological and electrophysiological criteria.

It also has been recently reported that FGF-2 can induce the proliferation of embryonic hippocampal progenitors (Ray et al., 1993). In that study, virtually pure neuronal cultures were derived, whereas, in our study, clones containing neurofilament positive cells also contained GFAP positive astrocytes, although usually in small numbers. What could account for these differences? On the one hand, Ray et al. (1993) point out that E18 fetal hippocampi are essentially homogeneous, consisting mainly of pyramidal neurons and this could reflect differences in the potentiality of precursors isolated from the embryonic hippo- 

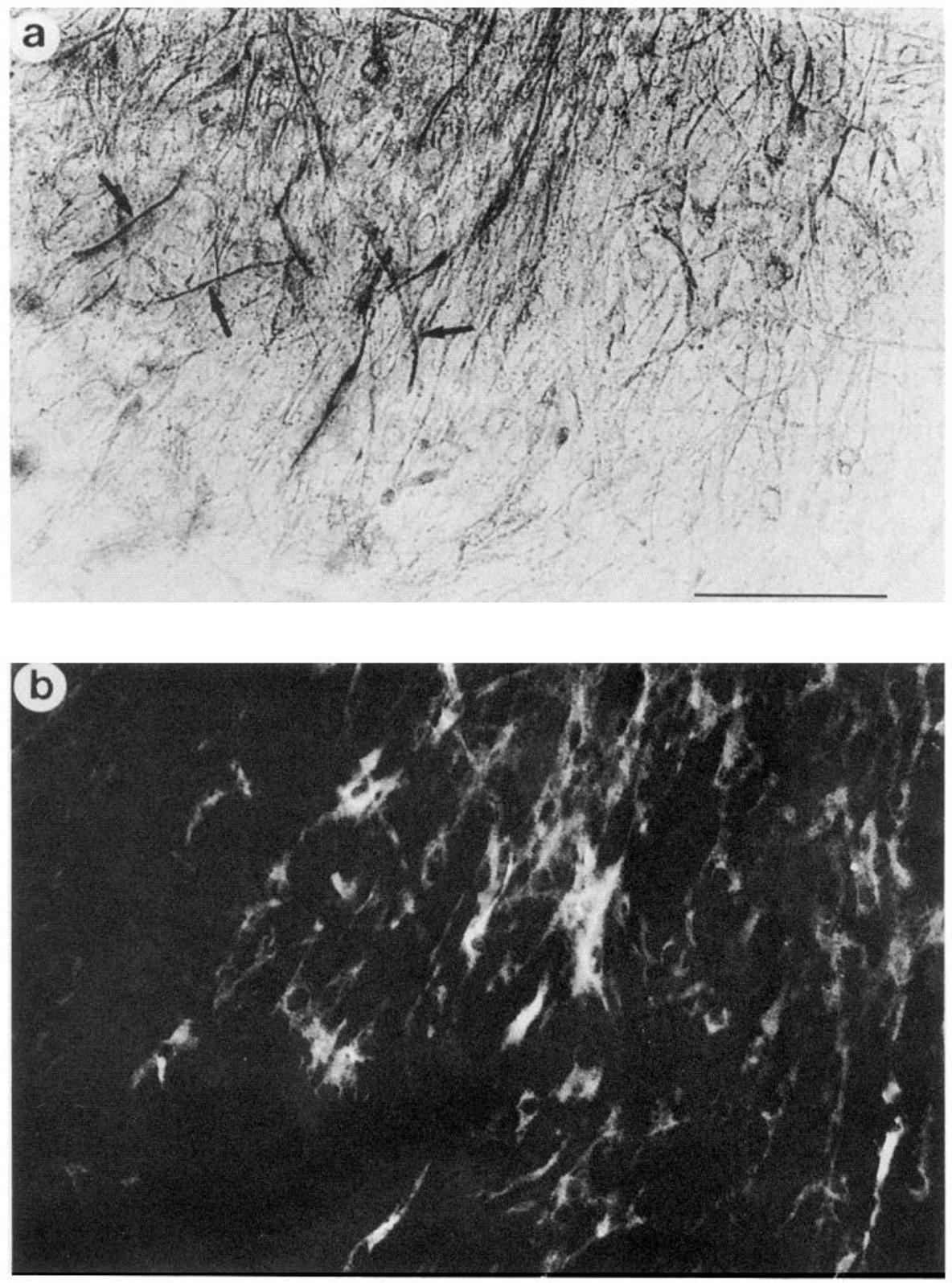

Figure 5. Photomicrographs of the same clone derived from FGF-2 treated E17 cerebral cells stained by immunoperoxidase for the expression of neurofilament $(a)$ and by immunofluorescence for the expression of GFAP $(b)$. Large numbers of neurofilament positive (arrows) and GFAP positive cells are present. Scale bar, $100 \mu \mathrm{m}$. campus and cerebrum. Although this may be true, Ray and Gage (1994) have very recently reported that spinal cord neuroblasts also proliferate in response to FGF-2, suggesting that this response is not unique to the hippocampus. Alternatively, differences between the culture systems employed by Ray et al. (1993) and Ray and Gage (1994), as opposed to those of the present study, could be important. Such variables include differences in the seeding density, differences in the basal media used and the fact that the former experiments were conducted using plates coated with cationic substrate, each of which could affect signalling pathways. In addition, our cultures were grown in the presence of serum which, in other culture systems, has been shown to potentiate the generation of GFAP positive astrocytes from progenitor cells (Raff et al., 1984). In contrast, cultures grown in serum-free media, as used by Ray et al. (1993), may not support either the survival or the proliferation of nonneuronal cells. This would imply that environmental factors can influence the spectrum of differentiated phenotypes generated from precursor populations.
Indications of an increased commitment in E17 precursors compared to E10 was also evident in the large number of glial restricted precursors identified at E17. Over $70 \%$ of the clones generated from the E17 cerebral cortex contained large numbers of astrocytes without neurons, indicating that they were probably derived from committed glial progenitors. The large number of glial restricted clones detected was not surprising, as, at E17, this is the predominant cell type being produced. This finding, however, is in contrast to previous work, which suggested that the percentage of committed astrocytic precursors present within the cerebrum of the rat at E16 may be very low (Williams et al., 1991). However, that study also identified a large percentage of clones which contained only undifferentiated cells. It is conceivable that these cells were, in fact, committed to the astroglial lineage but lacked the appropriate signals for their differentiation. These signals remain unknown but it has been suggested they are positively associated with high cell density (Kilpatrick et al., 1993).

One of the major findings of this study is that committed glial 
precursors respond either to FGF-2 or to EGF, whereas multipotential precursors only respond to FGF-2. Thus, subpopulations of neural precursors were identified on the basis of their growth factor responsiveness. The idea that EGF stimulates predominantly glial-restricted precursors is consistent with its known role in stimulating the proliferation and differentiation of cells of the glial cell lineage. (Leutz and Schachner, 1981; Raff et al., 1983; Almazan et al., 1985). Our findings differ from other reports in which EGF, without serum, induced the proliferation and differentiation of multipotential precursors isolated from either the E14 or adult mouse brain (Reynolds and Weiss, 1992; Reynolds et al., 1992). These differences are hard to reconcile, although it is of interest that these latter experiments were not performed at the level of a single cell plated per well. This may indicate, as for our high density cultures stimulated with EGF, that the generation of neurons resulted from the production of endogenous factor(s), possibly FGF, produced by EGF-responsive accessory cells. This view is supported by the finding that the generation of neurons in the EGF stimulated high density cultures was inhibited by $\operatorname{Ins}_{6}$, an agent previously reported to inhibit the binding of FGF-2 to its extracellular receptors (Sherman et al., 1993). Alternatively, it could be that there is a population of EGF-responsive multipotential precursors which has not been detected by clonal analysis in our study, either because of profound differences in the responsiveness of precursor populations isolated from the cerebrum and striatum or because the frequency of the EGF-responsive population is very low. The latter is feasible, as the reported frequency of the EGF-responsive cells is as low as 1 in a 1000 in the E14 striatum (Reynolds et al., 1992). It is also possible that the multipotential, FGF-2 responsive, E 17 precursor is related to the neuronal/astroglial progenitor recently identified, and shown to proliferate in response to FGF-2, by Vescovi et al. (1993). It will be of particular interest to determine if environmental conditions can be identified which induce the generation of oligodendrocytes from either of these precursors; to date, oligodendrocytes have not been identified in the derived clones (Vescovi et al., 1993; Kilpatrick, unpublished observations).

This study confirms the value of assessing the specific activities of growth factors upon precursor cells at the single cell level. It also establishes that the intrinsic developmental potential of CNS derived multipotential precursors varies during ontogeny. Together, these findings suggest the need for a more formal analysis of the growth potential of CNS precursors identified at other ages, including the adult (Reynolds and Weiss, 1992; Richards et al., 1992), if we are to understand the precise mechanisms involved in the proliferation and differentiation of precursor cells during development and the mechanisms which inhibit their differentiation within the adult brain. The resolution of these issucs is not only of fundamental interest but could also facilitate the development of strategies designed to repopulate the degenerating brain with newly differentiated cells, generated from precursor cells.

\section{References}

Almazan G, Honegger P, Matthieu J-M, Guentert-Lauber B (1985) Epidermal growth factor and bovine growth hormone stimulate differentiation and myelination of brain cell aggregates in culture. Brain Res 353:257-264.

Anchan RM, Reh TA, Angello J, Balliet A, Walker M (1991) EGF and $\mathrm{TGF}-\alpha$ stimulate retinal neuroepithelial cell proliferation in vitro. Neuron 6:923-936.

Angevine JB Jr, Sidman RL (1961) Autoradiographic study of cell migration during histogenesis of cerebral cortex in the mouse. Nature 192:766-788.

Drago J, Murphy M, Caroll SM, Harvey RP, Bartlett PF (1991a) Fibroblast growih factor-mediated proliferation of central nervous system precursors depends on endogenous production of insulin-like growth factor I. Proc Natl Acad Sci USA 88:2199-2203.

Drago J, Murphy M, Bailey KA, Bartiett PF (1991b) A method for the isolation of purified murine neuroepithelial cells from the developing mouse brain. J Neurosci Methods 37:251-256.

Grove EA, Williams BP, Li D-Q, Hajihosseini M, Friedrich A, Price J (1993) Multiple restricted lineages in the embryonic rat cerebral cortex. Development 117:553-561.

Kilpatrick TJ, Bartlett PF (1993) Cloning and growth of multipotential neural precursors: requirements for proliferation and differentiation. Neuron 10:255-265.

Kilpatrick TJ, Talman PS, Bartlett PF (1993) The differentiation and survival of murine neurons in vitro is promoted by soluble factors produced by an astrocytic cell line. J Neurosci Res 35:147-161.

Leutz A, Schachner M (1981) Epidermal growth factor stimulates DNA-synthesis of astrocytes in primary cerebellar cultures. Cell Tissue Res 220:393-404.

Lillien L, Cepko C (1992) Control of proliferation in the retina: temporal changes in responsiveness to FGF and TGFr. Development 115:253-266.

Lois C, Alvarez-Buylla A (1993) Proliferating subventricular zone cells in the adult mammalian forebrain can differentiate into neurons and glia. Proc Natl Acad Sci USA 90:2074-2077.

Luskin MB, Pearlman AL, Sanes JR (1988) Cell lineage in the cerebral cortex of the mouse studied in vivo and in vitro with a recombinant retrovirus. Neuron 1:635-647.

Luskin MB, Parnavelas JG, Barfield JA (1993) Neurons, astrocytes, and oligodendrocytes of the rat cerebral cortex originate from separate progenitor cells: an ultrastructural analysis of clonally related cells. J Neurosci 13:1730-1750.

Maric D, Maric I, Ma W, Barker JL (1992) Cell cycle gradients exist in the rat central nervous system during embryonic development. Int J Dev Neurosci 10[Suppl 1]:94.

Mehler MF, Rozental R, Dougherty M, Spray DC, Kessler JA (1993) Cytokine regulation of neuronal differentiation of hippocampal progenitor cells. Nature 362:62-65.

Morshead CM, van der Kooy D (1992) Postmitotic death is the fate of constitutively proliferating cells in the subependymal layer of the adult mouse brain. J Neurosci 12:249-256.

Murphy M, Drago J, Bartlett PF (1990) Fibroblast growth factor stimulates the proliferation and differentiation of neural precursor cells in vitro. J Neurosci Res 25:463-475.

Nurcombe V, Ford MD, Wildschut JA, Bartlett PF (1993) Developmental regulation of neural response to FGF-1 and FGF-2 by heparan sulfate proteoglycan. Science 260:103-106.

Price J, Turner DL, Cepko CL (1987) Lineage analysis in the vertebrate nervous system by retrovirus-mediated gene transfer. Proc Natl Acad Sci USA 84:156-160.

Price J, Thurlow L (1988) Cell lineage in the rat cerebral cortex: a study using retroviral-mediated gene transfer. Development 104:473482.

Raff MC, Abney ER, Cohen J, Lindsay R, Noble M (1983) Two types of astrocytes in cultures of developing rat white matter: differences in morphology, surface gangliosides, and growth characteristics. J Neurosci 3:1289-1300

Raff MC, Williams BP, Miller RH (1984) The in vitro differentiation of a bipotential glial progenitor cell. EMBO J 3:1857-1864.

Ray J, Gage FH (1994) Spinal cord astrocytes proliferate in response to basic fibroblast growth factor. J Neurosci 14:3548-3564.

Ray J, Peterson DA, Schinstine M, Gage FH (1993) Proliferation, differentiation and long-term culture of primary hippocampal neurons. Proc Natl Acad Sci USA 90:3602-3606.

Reynolds BA, Weiss S (1992) Generation of neurons and astrocytes from isolated cells of the adult mammalian central nervous system. Science 255:1707-1710.

Reynolds BA, Tetzlaff W, Weiss S (1992) A multipotent EGF-responsive striatal embryonic progenitor cell produces neurons and astrocytes. J Neurosci 12:4565-4574.

Richards LJ, Kilpatrick TJ, Bartlett PF (1992) De novo generation of neuronal cells from the adult mouse brain. Proc Natl Acad Sci USA 89:8591-8595. 
Sanes JR, Rubenstein JLR, Nicolas J-F (1986) Use of a recombinant retrovirus to study post-implantation cell lineage in mouse embryos. EMBO J 5:3133-3142.

Sherman L, Stocker KM, Morrison R, Ciment G (1993) Basic fibroblast growth factor acts intracellularly to cause the differentiation of avian neural crest-derived Schwann cell precursors into melanocytes. Development 118:1313-1326.

Temple $S$ (1989) Division and differentiation of isolated CNS blast cells in microculture. Nature 340:471-473.
Vescovi AL, Reynolds BA, Fraser DD, Weiss S (1993) bFGF regulates the proliferative fate of unipotent (neuronal) and bipotent (neuronal/ astroglial) EGF-generated CNS progenitor cells. Neuron 11:951-966.

Walsh C, Cepko CL (1992) Widespread dispersion of neuronal clones across functional regions of the cerebral cortex. Science 255:434 440.

Williams BP, Read J, Price J (1991) The generation of neurons and oligodendrocytes from a common precursor cell. Neuron 7:685-693. 